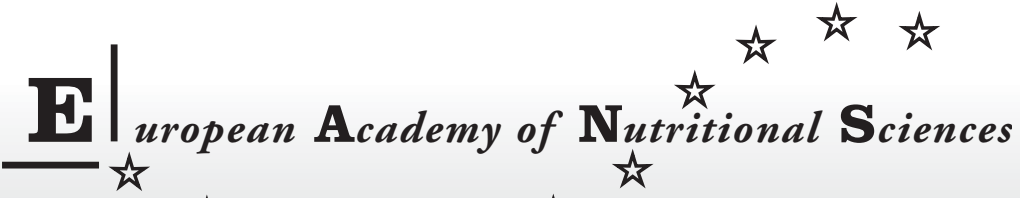 th th th th
}

\section{EANS Membership Application Form}

\section{Membership of the European Academy of Nutritional Sciences:}

Active members of the Academy (yearly fee EUR 20.-): eligible as active members of the Academy are individuals, who have distinguished themselves in sciences related to nutrition.

\section{EANS application procedures:}

Candidates may apply individually for membership by completing the application form below or online at: www.eans.net. A one-page CV and a list of your 10 most important publications (title and reference) must be included in your application. When the Secretary concludes that all the formal criteria have been met, he will then ask the Presidium for the applicant to be presented for election to the General Assembly.

\section{Application form:}

Name:

Company/Institution:

\section{Address:}

Postal code:

City:

Country:

Tel.:

Fax:

E-Mail:

2 main areas of expertise:

Additional comments:

\section{Please submit this form to:}

EANS Secretariat

Dr. Pierre R. Guesry

Nestlé Research Center

P.O. Box 44

Vers-chez-les-Blanc

CH-1000 Lausanne 26 (Switzerland)

E-Mailpguesry@maltanet.net 